\title{
BMJ Open Impact of a health campaign on Chinese public awareness of stroke: evidence from internet search data
}

\author{
Man Cao (D) , ${ }^{1}$ Tianjia Guan, ${ }^{1}$ Xueyan Han, ${ }^{2}$ Bingjie Shen, ${ }^{1}$ Baohua Chao, ${ }^{3}$ \\ Yuanli Liu ${ }^{1}$
}

To cite: Cao M, Guan T, Han X, et al. Impact of a health campaign on Chinese public awareness of stroke: evidence from internet search data. BMJ Open 2021;11:e054463. doi:10.1136/ bmjopen-2021-054463

- Prepublication history and additional supplemental material for this paper are available online. To view these files, please visit the journal online (http://dx.doi.org/10.1136/ bmjopen-2021-054463).

Received 15 June 2021 Accepted 25 October 2021

\section{Check for updates}

(C) Author(s) (or their employer(s)) 2021. Re-use permitted under CC BY-NC. No commercial re-use. See rights and permissions. Published by BMJ.

${ }^{1}$ School of Health Policy and Management, Chinese Academy of Medical Sciences \& Peking Union Medical College, Beijing, China

${ }^{2}$ Department of Medical Statistics, Peking University First Hospital, Beijing, China ${ }^{3}$ National Health Commission of the People's Republic of China, Beijing, China

\section{Correspondence to}

Professor Yuanli Liu; liuyuanli_pumc@163.com and Dr Tianjia Guan; gtj@sph.pumc.edu.cn

\section{ABSTRACT}

Introduction Health campaigns have the potential to improve public awareness, but their impact can be difficult to assess. Internet search data provide information concerning online health information-seeking behaviour in the population and may serve as a proxy for public awareness to evaluate health campaigns. This study aimed to measure the impact of World Stroke Day (WSD) in China using Baidu search data.

Methods Daily search index values (SIV) for the term 'stroke' were collected from January 2011 to December 2019 using the Baidu Index platform. We examined the mean difference in SIV between the 4 weeks surrounding WSD (period of interest) and the rest of the year (control period) for each year by t-test analysis. The mean difference between the period of interest and the control period was also calculated. The joinpoint regression model was used to analyse the trends of internet search activity 30 days before and after WSD for each year (2011-2019). Finally, the top and rising queries related to stroke during the week of the campaign in 2020 were summarised. Results A significant mean increase in SIV of 418.5 (95\% Cl: 298.8 to 538.2) for the period of interest surrounding WSD was observed, $36.2 \%$ greater than the SIV during the control period (2011-2019). Short-term joinpoint analysis showed a significant increase in SIV 3 days before WSD, a peak on WSD and a decrease to the precampaign level 3 days after WSD. The rising related queries suggested that the public had increasing concerns about stroke warning signs, stroke prevention and stroke recovery during the campaign. Conclusions The WSD campaign increased internet search activity. These research techniques can be applied to evaluation of other health campaigns. Advancing understanding of public demand will enable tailoring of the campaign and strengthen health management.

\section{INTRODUCTION}

Health campaigns are organised communication activities that aim to raise awareness concerning specific health-related themes and influence health behaviour. ${ }^{1}$ As a populationbased preventive and intervention strategy, health campaigns - such as health awareness days, weeks and months-have the potential to improve public health awareness and alleviate the burden of disease. ${ }^{23}$ Despite the frequency of health campaigns conducted

\section{Strengths and limitations of this study}

- A key strength is that this is the first study to evaluate the impact of the World Stroke Day campaign and to explore public priorities relating to stroke using internet search data in China.

- Our research techniques can potentially be applied to evaluation of other health campaigns.

- We could only evaluate the impact of health campaign on internet search activity for people with internet access.

- Online search activity cannot necessarily be extrapolated to attainment of valid information from the internet nor to offline health information-seeking behaviours.

by the government and professional associations, there are relatively few ways to assess their impacts. Conventional epidemiological studies are often dependent on bespoke, large scale data collection, which are costly, resourceintensive and limited in geographical scope. ${ }^{4-8}$ Consequently, an alternative real-time and lowcost method is needed to monitor public awareness before, during and after a campaign.

The internet and online search engines have become an increasingly popular source of health information; they potentially enhance knowledge and awareness of specific healthrelated topics, such as prevention, symptoms and medical advice. ${ }^{9} 10$ Additionally, online search queries can reveal the public's underlying health perspectives and capture reluctance to participate in a survey. ${ }^{11} 12 \mathrm{It}$ has been estimated that $64.2 \%$ of the global population had internet access by December $2020 .{ }^{13}$ Because of the wide coverage, rapid updating, low cost and anonymity of internet data, several studies have used internet search data to evaluate the impacts of Breast Cancer Month, ${ }^{14-16}$ Colorectal Cancer Month, ${ }^{17}$ Autism Awareness Month ${ }^{18}$ and World Hepatitis Day ${ }^{19}$; the results indicated a significant increase in online search activity, suggesting 
increased awareness. The public's concerns and priorities regarding a specific topic can also be assessed by analysing related search queries. ${ }^{2021}$ Internet search activity can be used as a proxy for public awareness of health themes, which has the potential for health-campaign evaluation.

Stroke is the leading cause of death and disability in China. ${ }^{22} 23$ The incidence of first-ever stroke in adults is increasing at an annual rate of $8.3 \%$ in China. ${ }^{24}$ To tackle the high burden of stroke, the World Stroke Day (WSD) campaign, an international health campaign that is undertaken on 29 October of each year, ${ }^{25}{ }^{26}$ was launched by the China Stroke Prevention and Treatment Project in 2011 in China. Although WSD has been held for several years, its impact on public awareness is unknown. The Baidu Index offers a novel method for estimating internet search activity for specific terms over time and has been used in epidemiological surveillance in China. ${ }^{27-30}$ It is derived from search frequencies on the Baidu search engine with the highest market share in China $(90.9 \%$ penetration rate). ${ }^{31-33}$ Therefore, Baidu search activity may be potentially used to monitor public awareness of stroke to assess the impact of WSD.

We evaluated the impact of the WSD campaign using Baidu search data in China. We hypothesised that WSD stimulates online health information-seeking behaviour. We also hypothesised that the public's stroke-related priorities would be revealed during implementation of WSD.

\section{METHODS}

\section{Data sources}

This research involved free, publicly available, de-identified, online information from the Baidu Index platform. We used search index values (SIV), top related queries and rising related queries provided by the Baidu Index to examine internet search activity and public priorities, respectively.

The SIV is defined as the weighted sum of the search frequency for specific search terms entered by internet users; it is available daily, weekly or yearly and at various levels (ie, municipal, provincial or national). ${ }^{27}{ }^{34}$ The SIV is the result of exponential processing of search volumes for specific search terms. In this study, we used internet search activity for stroke as a proxy for public awareness to evaluate the impact of WSD.

The top related queries are the terms most frequently searched with the search term entered by internet users within 1 week. The rising related queries are the terms searched with the search term entered by internet users; and they are with the greatest growth in search volume in the requested week, compared with the previous week. ${ }^{27}$

\section{Data collection}

\section{Search term selection}

Search terms were selected to measure public interest in a health campaign. The health-related concern included in the name of the health campaign was prioritised over a synonym or phrase with a similar meaning. ${ }^{35}$ We selected two search terms for stroke (ie, “卒中' and ‘脑卒中' in Chinese) to reflect public interest in WSD (“世界卒中日” in Chinese) and summed their daily SIV.

\section{Collection of SIV data}

For long-term analysis, we extracted the daily SIV for stroke from January 2011 to December 2019, without any restriction in location. We selected days in the 4 weeks surrounding WSD (ie, the week before WSD, the week of WSD and the 2 weeks after WSD) as the period of interest. ${ }^{36}$ Days in the remaining weeks of the corresponding year were used as the control. For short-term analysis, we collected the daily SIV for stroke 30 days before and after WSD (61 total days). The time scale was selected to capture any increased online search queries prior to WSD, as well as the duration of any effect in the subsequent 30 days. This was performed separately for each year (2011-2019).

\section{Collection of top and rising related queries data}

We collected the top 10 related queries and the rising related queries for stroke ('脑卒中' in Chinese) from 26 October 2020 to 1 November 2020 (the week of WSD). Because the top related queries and rising related queries were available only for the most recent year, we collected the data for 2020 .

\section{Data analysis}

The t-test was used to evaluate the mean difference in SIV with the $95 \%$ CI between the 4 weeks of interest surrounding WSD and the other weeks of the year. This was performed separately for each year, from 2011 to 2019. Additionally, we calculated the difference in SIV for the period of interest and the control period as differences in percentage.

To examine the trend of internet search activity before, during and after WSD, the joinpoint regression model was used. This model identifies statistically significant time points, known as joinpoints, which represent significant changes in the linear slopes of the trend. The analysis is often used to calculate the annual per cent change (APC) in cancer incidence between two joinpoints; in recent years, it has been used to investigate the effects of health awareness campaigns on online health informationseeking behaviour. ${ }^{35} 3738$ In this study, the independent variable was the day, and the dependent variable was the natural logarithm of the daily SIV fit to a linear regression line. The percentage daily change in SIV was calculated and recorded as the APC by the software. The analysis was preset to identify a minimum of zero and a maximum of three joinpoints. This maximum was chosen because of the expected predicted pattern. A permutation test was performed as the model selection method with an overall significance level of 0.05 .

We described the top 10 related queries and the rising related queries for stroke ('脑卒中' in Chinese) during the campaign to understand public's perspective regarding stroke. 
Table 1 Mean differences in search index values (SIV) for stroke between the period of interest and the control period from 2011 to 2019.

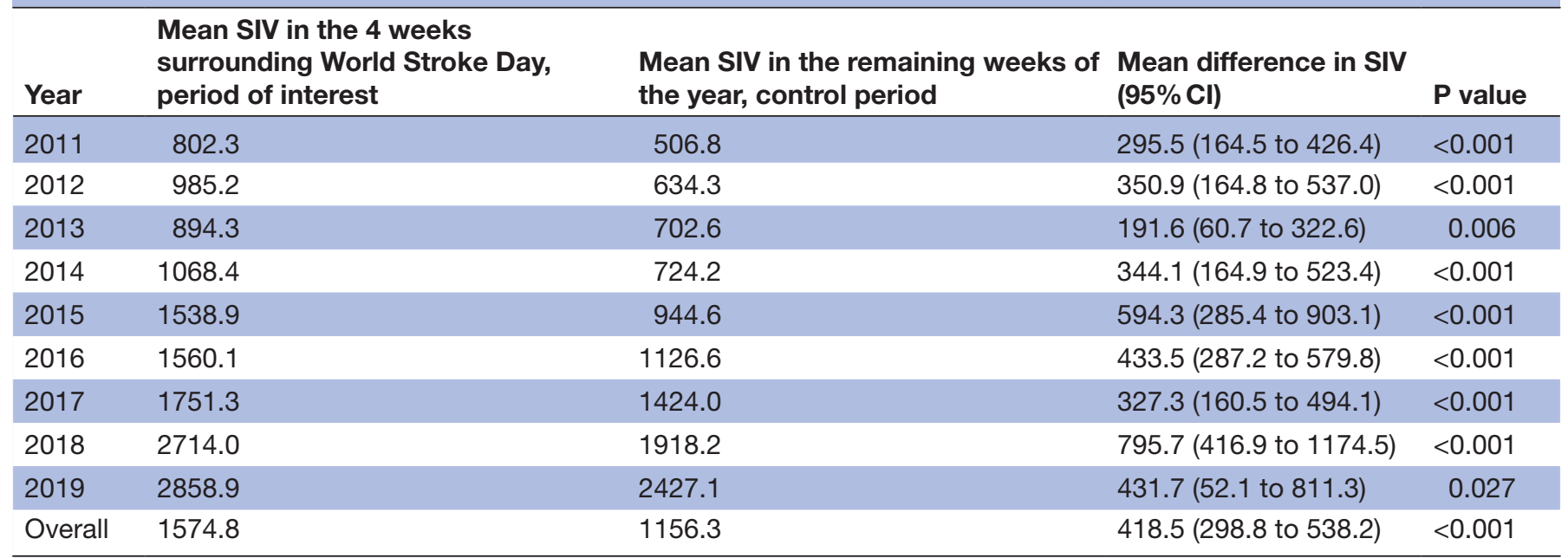

We conducted joinpoint regression analysis using Joinpoint Trend Analysis software V.4.8.0.1 (Statistical Research and Applications Branch, National Cancer Institute), and t-tests and Spearman's rank correlation analysis using SAS V.9.4 (SAS Institute).

\section{Patient and public involvement statement}

Patients or the public were not involved in the design, or conduct of our study.

\section{RESULTS}

Impact of WSD on internet search activity

WSD significantly affected internet search activity in each year. A positive and statistically significant mean difference was observed in SIV for stroke between the period of interest and the control period (table 1). The mean difference ranged from 191.6 (95\% CI: 60.7 to 322.6 ) in 2013 to 795.7 (95\% CI: 416.9 to 1174.5 ) in 2018; overall, it was 418.5 (95\% CI: 298.8 to 538.2 ). The mean percentage increase in SIV was $36.2 \%$ for the period of interest, compared with the control period (2011-2019). In seven major regions in China, the mean difference in SIV between WSD and the control periods was positive and statistically significant in all but South China. See online supplemental appendix 1 for details.

To examine changes in internet search activity before, during and after the campaign period, a joinpoint analysis was performed concerning the 30 days before and after WSD. The analysis identified three significant inflection joinpoints. Notably, there was a sharp increase in SIV from 3 days before WSD and a spike in SIV on WSD (29.55\% increase, $\mathrm{p}=0.031)$, reflecting increasing interest

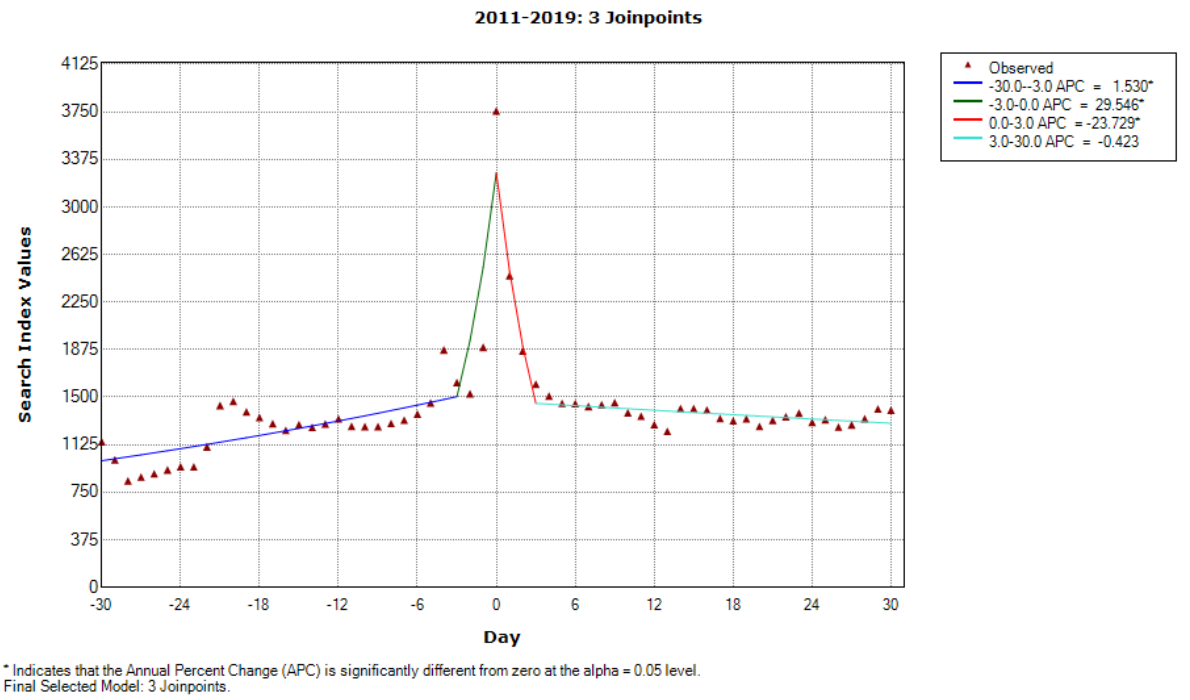

Figure 1 Changes in search index values (SIV) for stroke 30 days before and after World Stroke Day (2011-2019). Each data point indicates the mean SIV measured on the specified day from 2011 to 2019. Colour scheme: blue, first slope; green, second slope; red, third slope; mint green, fourth slope. 

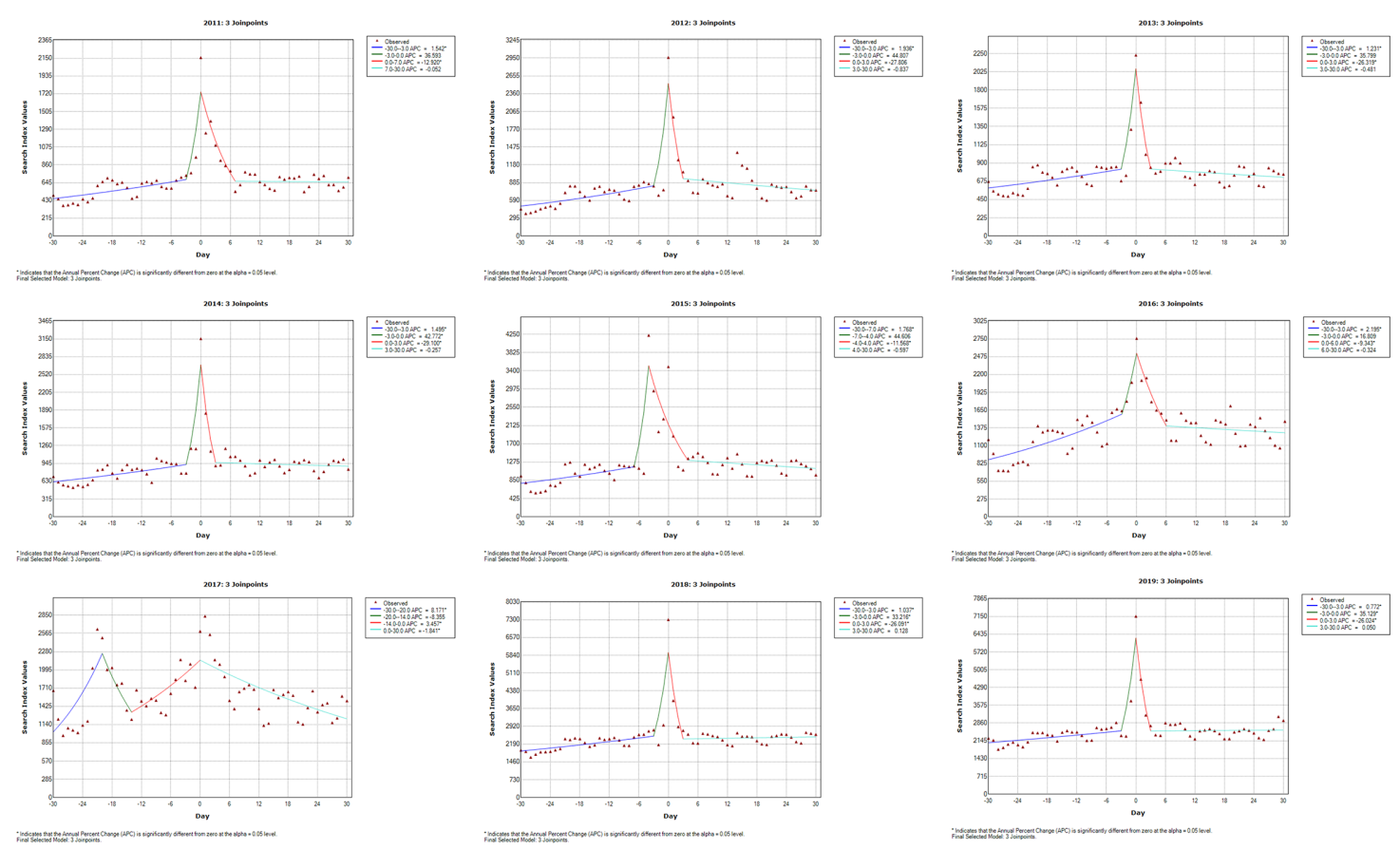

Figure 2 Changes in search index values (SIV) for stroke 30 days before and after World Stroke Day for each year. Each data point indicates the SIV measured on the specified day. Colour scheme: blue, first slope; green, second slope; red, third slope; mint green, fourth slope.

in searches prior to WSD (figure 1). A significant decrease in SIV $(23.73 \%, \mathrm{p}=0.012)$ was observed after WSD. The short-term temporal trends in SIV for each year were shown in figure 2 .

\section{Summary of public's stroke-related priorities}

The top related queries are indicative of public demand for information regarding specific topics, and the rising related queries reveal changes in public priorities, reflecting the impacts of campaigns or events. The top 10 related queries for stroke indicated that the public was interested in general stroke information, stroke risk factors and stroke effects during the week of WSD (table 2). Analysis of rising related queries for stroke suggested that Chinese internet users had increasing interest in stroke warning signs, stroke prevention, general stroke information and stroke recovery during the week of WSD (table 3).

\section{DISCUSSION}

\section{Main findings}

The WSD campaign stimulated increased internet search activity, which potentially enhance public knowledge and awareness. Furthermore, we found the stroke-related terms that public searched at the greatest growth during the campaign were categorised to stroke warning signs, stroke prevention and stroke recovery. To our knowledge, this is the first study of the impact of a health campaign on online health information-seeking behaviour in China; it is also the first study to explore public concerns and priorities regarding stroke by ranking stroke-related search queries.
The WSD campaign had a substantial impact on internet search activity in each year. These results were in agreement with previous reports of health-campaign evaluation based on Google Trend data. Scheres $e t a l^{39}$ reported a 23.3\% increase in search volume during the World Thrombosis Day period in the Netherlands, compared with the rest of the year. Lippi et $a l^{40}$ observed a $21 \%$ increase in the level of Google search activity worldwide

Table 2 Top 10 related queries for stroke during the week of World Stroke Day (26 October 2020 to 1 November 2020).

\begin{tabular}{cll}
\hline Rank & Category & Stroke (脑卒中) \\
\hline 1 & $\begin{array}{l}\text { General stroke } \\
\text { information }\end{array}$ & Cerebral infarction (脑梗) \\
\hline 2 & $\begin{array}{l}\text { General stroke } \\
\text { information }\end{array}$ & $\begin{array}{l}\text { How do you pronounce } \\
\text { stroke (卒怎么读) }\end{array}$ \\
\hline 3 & $\begin{array}{l}\text { Stroke risk factor } \\
\text { Atrial fibrillation (房颤) }\end{array}$ \\
\hline 5 & $\begin{array}{l}\text { General stroke } \\
\text { information }\end{array}$ & $\begin{array}{l}\text { Cerebral haemorrhage (脑 } \\
\text { 出血) }\end{array}$ \\
\hline 6 & $\begin{array}{l}\text { General stroke } \\
\text { information }\end{array}$ & Stroke (中) \\
General stroke & Stroke (卒) \\
\hline 7 & $\begin{array}{l}\text { General stroke } \\
\text { information }\end{array}$ & Stroke (卒中) \\
\hline 9 & $\begin{array}{l}\text { General stroke } \\
\text { information } \\
\text { General stroke } \\
\text { information }\end{array}$ & Cerebral infarction (脑梗塞) \\
\hline 10 & Cerebral infarction (脑梗死) \\
\hline
\end{tabular}


Table 3 Rising related queries for stroke during the week of World Stroke Day (26 October 2020 to 1 November 2020).

\begin{tabular}{|c|c|c|}
\hline Rank & Category & Stroke (脑卒中) \\
\hline 1 & $\begin{array}{l}\text { General stroke } \\
\text { information }\end{array}$ & Stroke (卒中) \\
\hline 2 & Warning signs & Stroke 120 (卒中120) \\
\hline 3 & Stroke prevention & $\begin{array}{l}66 \text { items of health } \\
\text { literacy (健康66条) }\end{array}$ \\
\hline 4 & Stroke risk factor & $\begin{array}{l}\text { Acute water } \\
\text { intoxication (急性水 } \\
\text { 中毒) }\end{array}$ \\
\hline 5 & $\begin{array}{l}\text { General stroke } \\
\text { information }\end{array}$ & $\begin{array}{l}\text { What is stroke (什么是 } \\
\text { 脑卒中) }\end{array}$ \\
\hline 6 & Stroke recovery & $\begin{array}{l}\text { Stroke recovery (脑卒 } \\
\text { 中康复) }\end{array}$ \\
\hline 7 & $\begin{array}{l}\text { General stroke } \\
\text { information }\end{array}$ & $\begin{array}{l}\text { How to pronounce } \\
\text { stroke (卒怎么读) }\end{array}$ \\
\hline
\end{tabular}

during World Diabetes Day. Glynn et $a l^{15}$ showed that Breast Cancer Awareness Month campaign generated public interest in the disease. Increased internet search activity may be caused by information dissemination on a topic through online or offline channels during health campaigns. People interested in the specific health issue were more likely to seek detailed information online. However, Ling and $\mathrm{Lee}^{38}$ reported that a campaign aiming to increase awareness of stroke in Canada, known as Make Health Last, was not associated with the public's online search behaviour. Possible reasons for the inconsistent findings from Make Health Last in Canada and WSD in China may include differences in campaign organisers, delivery channels and potential impacts not captured by the internet. For campaign organisers, the Make Health Last campaign was led by the Heart and Stroke Foundation in Canada, while the WSD campaign was launched by the government with more authority and it was a communitybased campaign across China. For delivery channels, the Make Health Last campaign was delivered only through online platforms (Canadian Broadcasting Corporation), while the delivery channels for WSD included both online and offline, such as pamphlets, physician referrals, health lecture hall, television, website and social media. The WSD campaign supported by the Chinese government and promoted through a variety of channels had a positive effect on stimulating public online search behaviour. Moreover, we found that increased online search activity during WSD was not significant in South China. This may be due to the lowest prevalence of stroke in the South compared with other regions, ${ }^{41}$ or to greater educational strategies throughout the year which would keep interest in the public and decrease the relative peak caused by WSD.

Whenever a significant increase in online search activity was found, it was followed by a decrease, indicating that the effect was short-term, similar to the outcomes in other studies of Global Public Health Days. ${ }^{35} 37$ The increased internet search activity may be due to the related physician referrals, announcements and media attention several days before the actual date, which stimulated public interest in stroke to search for it on the internet. The decrease may be a result of three factors. First, the health campaign improved public knowledge and awareness of specific topics or prompted individuals to consult their physicians for medical advice, which led to reduced online search queries. Second, the impact may involve other online platforms used after searching. The website of the Dutch blood supply Sanquine was visited twice as often, and $54.6 \%$ more new donors were registered, in the 3 weeks surrounding World Blood Donor Day in 2016. ${ }^{42}$ The number of calls to a smoking helpline was approximately fivefold higher on National No Smoking Day, compared with the annual daily average in the UK. ${ }^{7}$ Mahroum et al reported that users tended to search for a topic on Google, and then interacted with it on Twitter. ${ }^{43}$ Therefore, the impact of the campaign may have been underestimated. Future studies should evaluate the impacts of health campaigns using various data streams. However, it is likely that a health awareness campaign is short-lived, and the public lose interest in the health topic after its conclusion.

It is essential that health campaigns be planned and implemented in accordance with the educational needs of the population. Our findings showed a rapid increase in public interest in stroke warning signs, prevention and recovery during the week of the campaign, compared with common levels of public concern regarding general stroke information, stroke risk factors and stroke effects. Therefore, people had increased interest in some types of health information, or the information provided during the campaign did not meet their needs. The public searched on the internet for a more comprehensive and detailed understanding. Recognition of stroke warning signs is vital, and intervention tools have been designed to promote an emergency response to stroke symptoms, such as the 'FAST' tool in English-speaking countries ${ }^{44}$ and 'Stroke 120' in China. 'Stroke 120' also prompts immediate activation of emergency medical services by dialling 120 in China. ${ }^{45}$ People showed increasing concern about 'Stroke 120' during the campaign, implying that advocacy should be strengthened in subsequent campaigns. Additionally, health literacy (eg, knowledge and belief literacy, behaviour literacy and skill literacy) is essential for disease prevention and control. ${ }^{46}$ Notably, the mortality and disability rates from stroke are observed higher in China than in well-developed countries. ${ }^{47} 48$ Our findings also suggested that comprehensive information regarding stroke recovery should be delivered during the campaign, especially in areas with a high disability rate. Our findings will enable health authorities and stroke-related non-governmental organisations to tailor publicity and education strategies and strengthen health management.

In 2017, there was a spike in SIV for stroke on the 21 days before the WSD in addition to the peak on the WSD (figure 2), possibly because of a news report that 
Table 4 Spearman's rank correlations between media index values and search index values for stroke 30 days before and after World Stroke Day from 2011 to 2019.

\begin{tabular}{lll}
\hline Year & Spearman's rho & P value \\
\hline 2011 & 0.549 & $<0.001$ \\
2012 & 0.539 & $<0.001$ \\
2013 & 0.651 & $<0.001$ \\
2014 & 0.762 & $<0.001$ \\
2015 & 0.723 & $<0.001$ \\
2016 & 0.651 & $<0.001$ \\
2017 & 0.374 & $<0.001$ \\
\hline 2018 & 0.782 & $<0.001$ \\
2019 & 0.711 & $<0.001$ \\
\hline Overall & 0.752 & $<0.001$ \\
\hline
\end{tabular}

drew widespread public attention instead of the WSD. A student was reported to be comatose and admitted to hospital with a diagnosis of stroke, because of playing games continuously for 3 days during the Mid-Autumn Festival holiday. ${ }^{49}$ Therefore, media reports may affect online information-seeking behaviours, as suggested by preview works. Disease-related announcements by public figures, such as a diagnosis or death, had an impact on internet disease-related information-seeking behaviour. $^{3950-52}$ This suggested that health promotion activities, especially multimedia and web-based awareness campaigns regarding a specific disease, should be initiated or increased promptly after a major media event to maximise their influence on the general public.

The volume of stroke-related news reports increased during the WSD campaign. We found a significant correlation between the media index value and SIV 30 days before and after WSD (Spearman's rho=0.752, p<0.001) (table 4 ). The media index value was provided by the Baidu Index and defined as the volume of news reports containing the identified Baidu search activity terms in their headlines. ${ }^{27} 32$ Similarly, media coverage was reportedly associated with internet search activity. ${ }^{53}$ Media coverage may promote dissemination of knowledge and increase public awareness; therefore, health-campaign organisers should leverage this to provide accurate, authoritative, up to date and timely information.

We compared online search queries with the level of health literacy and observed a similar temporal trend from 2012 to 2019 in China (figure 3). National-level annual health literacy data were obtained from National Health Literacy Surveillance on the website of the National Health Commission. ${ }^{55}$ This result suggested online search activity improved public knowledge and awareness, an important component of health literacy, but further surveys are needed. Moreover, some studies showed an increase in sales of in-home HIV tests during World AIDS Day ${ }^{56}$ and an increase in the number of thrombolytic treatments after stroke days. ${ }^{57}$ Future

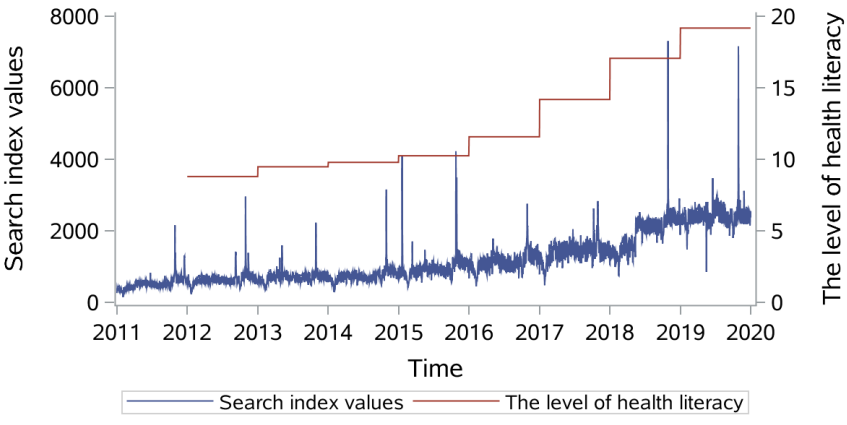

Figure 3 Trends of search index values (SIV) and the level of health literacy from 2011 to 2019 . Blue line, SIV of stroke from 2011 to 2019; red line, level of health literacy from 2012 to 2019 .

studies could improve on our study design to more accurately capture the value of information provided to the users by the internet.

\section{Limitations}

This study had several limitations. First, the online information-seeking behaviour was captured for only the portion of the population with internet access; offline and face-to-face information seeking behaviour, such as consulting a health professional, could not be evaluated. Second, we focused on search query volumes on the Baidu search engine; future studies should include other sources, such as Weibo, WeChat and Zhihu. ${ }^{424}$ Third, two terms used in the Chinese campaign name were selected to estimate online information-seeking behaviours for stroke (ie, '卒中' and '脑卒中' in Chinese). In future studies, terms from the campaign theme or slogan should be included to accurately capture changes in search behaviours. Fourth, we could not analyse the changes in search queries for stroke during the same period of the year prior to establishment of WSD, because Baidu Index data were only available beginning in 2011 and WSD was first held in 2011 in China. Finally, our findings do not necessarily translate to attainment valid information and increases in offline health information-seeking behaviours; they only highlight the effect of health awareness campaigns on online search activity in the most used search engine, which have the potential to raise public awareness.

\section{CONCLUSIONS}

Internet search data enable monitoring of online health information-seeking behaviour, which potentially reflects public awareness, especially in regions with high internet penetration. Our findings show that the WSD campaign had a positive impact on internet search activity, and our research techniques can be applied to evaluation of other health campaigns. People showed increasing concern regarding stroke warning signs, stroke prevention and stroke recovery during the campaign. Advancing understanding of public demand will enable tailoring of the campaign and strengthen health management. 
Contributors MC, TG and YL designed the study. MC collected the original Baidu Index data in China, reviewed the literature, performed the analyses and wrote the first draft of the manuscript. TG, BC, XH, BS and YL critically revised the manuscript. All authors contributed to the interpretation of data and the final approved version. YL and TG accepts full responsibility for the finished work and/or the conduct of the study, had access to the data, and controlled the decision to publish.

Funding This study was funded by the National Natural Science Foundation of China (No. 71532014).

Competing interests None declared.

Patient consent for publication Not applicable.

Provenance and peer review Not commissioned; externally peer reviewed.

Data availability statement Data are available upon reasonable request.

Supplemental material This content has been supplied by the author(s). It has not been vetted by BMJ Publishing Group Limited (BMJ) and may not have been peer-reviewed. Any opinions or recommendations discussed are solely those of the author(s) and are not endorsed by BMJ. BMJ disclaims all liability and responsibility arising from any reliance placed on the content. Where the content includes any translated material, BMJ does not warrant the accuracy and reliability of the translations (including but not limited to local regulations, clinical guidelines, terminology, drug names and drug dosages), and is not responsible for any error and/or omissions arising from translation and adaptation or otherwise.

Open access This is an open access article distributed in accordance with the Creative Commons Attribution Non Commercial (CC BY-NC 4.0) license, which permits others to distribute, remix, adapt, build upon this work non-commercially, and license their derivative works on different terms, provided the original work is properly cited, appropriate credit is given, any changes made indicated, and the use is non-commercial. See: http://creativecommons.org/licenses/by-nc/4.0/.

ORCID iD

Man Cao http://orcid.org/0000-0001-9521-6311

\section{REFERENCES}

1 Masiulienè L, Looney J, Aertgeerts H. The key features of successful awareness raising campaigns. Brussels, Belgium: European Literacy Policy Network, 2015.

2 Kaste M, Norrving B. From the world stroke day to the world stroke campaign: one in six: act now! Int J Stroke 2010;5:342-3.

3 Grilli R, Ramsay C, Minozzi S. Mass media interventions: effects on health services utilisation. Cochrane Database Syst Rev 2002;1:Cd000389.

4 Mellon L, Doyle F, Rohde D, et al. Stroke warning campaigns: delivering better patient outcomes? A systematic review. Patient Relat Outcome Meas 2015;6:61-73.

5 Nehme Z, Andrew E, Bernard S, et al. Impact of a public awareness campaign on out-of-hospital cardiac arrest incidence and mortality rates. Eur Heart J 2017;38:1666-73.

6 Tibazarwa K, Ntyintyane L, Sliwa K, et al. A time bomb of cardiovascular risk factors in South Africa: results from the heart of soweto study "Heart Awareness Days". Int J Cardiol 2009;132:233-9.

7 Owen L, Youdan B. 22 years on: the impact and relevance of the UK no smoking day. Tob Control 2006;15:19-25.

8 Haesebaert J, Laude C, Termoz A, et al. Impact of a theory-informed and user-centered stroke information campaign on the public's behaviors, attitudes, and knowledge when facing acute stroke: a controlled before-and-after study. BMC Public Health 2020;20:1712.

9 Barros JM, Duggan J, Rebholz-Schuhmann D. The application of Internet-based sources for public health surveillance (infoveillance): systematic review. J Med Internet Res 2020;22:e13680.

10 Scantlebury A, Booth A, Hanley B. Experiences, practices and barriers to accessing health information: a qualitative study. Int $J$ Med Inform 2017;103:103-8.

11 Stephens-Davidowitz S. Everybody lies: big data, new data, and what the internet can tell us about who we really are. New York: Dey Street Books, 2017.

12 Ayers JW, Althouse BM, Dredze M. Could behavioral medicine lead the web data revolution? JAMA 2014;311:1399-400.

13 Miniwatts Marketing Group. World Internet users statistics and population statistics 2021 year-Q1 estimates, 2020. Available: https://www.internetworldstats.com/stats.htm [Accessed Feb 3rd 2021].

14 Schootman M, Toor A, Cavazos-Rehg P, et al. The utility of google trends data to examine interest in cancer screening. BMJ Open 2015;5:e006678.
15 Glynn RW, Kelly JC, Coffey N, et al. The effect of breast cancer awareness month on internet search activity--a comparison with awareness campaigns for lung and prostate cancer. BMC Cancer 2011;11:442.

16 Jacobsen GD, Jacobsen $\mathrm{KH}$. Health awareness campaigns and diagnosis rates: evidence from national breast cancer awareness month. J Health Econ 2011;30:55-61.

17 Pantel HJ, Kleiman DA, Kuhnen AH, et al. Has national colorectal cancer awareness month increased endoscopy screening rates and public interest in colorectal cancer? Surg Endosc 2021;35:398-405.

18 DeVilbiss EA, Lee BK. Brief report: trends in US national autism awareness from 2004 to 2014: the impact of national autism awareness month. J Autism Dev Disord 2014;44:3271-3.

19 Ortiz-Martinez Y, Rios-González CM. Global impact of the world hepatitis day 2016: an evaluation using Google trends. J Infect Public Health 2017;10:690-1.

20 Cacciamani GE, Sebben M, Tafuri A, et al. Consulting 'Dr. Google' for minimally invasive urological oncological surgeries: A contemporary web-based trend analysis. Int J Med Robot 2021;17:e2250.

21 McLean S, Lennon P, Glare P. Internet search query analysis can be used to demonstrate the rapidly increasing public awareness of palliative care in the USA. BMJ Support Palliat Care 2019;9:40.

22 GBD 2017 Causes of Death Collaborators. Global, regional, and national age-sex-specific mortality for 282 causes of death in 195 countries and territories, 1980-2017: a systematic analysis for the global burden of disease study 2017. Lancet 2018;392:1736-88.

23 Feigin VL, Lawes CMM, Bennett DA, et al. Stroke epidemiology: a review of population-based studies of incidence, prevalence, and case-fatality in the late 20th century. Lancet Neurol 2003;2:43-53.

24 Guan T, Ma J, Li M, et al. Rapid transitions in the epidemiology of stroke and its risk factors in China from 2002 to 2013. Neurology 2017;89:53-61.

25 Mendis S. WorldStroke day 2009. Int J Stroke 2009;4:315-6.

26 Sandercock P. World Stroke Day - a day of global action. Int J Stroke 2018;13:779.

27 Baidu Index. The center for help on Baidu index, 2020. Available: http://index.baidu.com/v2/main/index.html\#/help [Accessed 16 Nov 2020].

28 Li K, Liu M, Feng Y, et al. Using Baidu search engine to monitor AIDS epidemics inform for targeted intervention of HIV/AIDS in China. Sci Rep 2019:9:320.

$29 \mathrm{Du}$ Z, Xu L, Zhang W, et al. Predicting the hand, foot, and mouth disease incidence using search engine query data and climate variables: an ecological study in Guangdong, China. BMJ Open 2017;7:e016263.

30 Tu B, Wei L, Jia Y, et al. Using Baidu search values to monitor and predict the confirmed cases of COVID-19 in China: - evidence from Baidu index. BMC Infect Dis 2021;21:98

$31 \mathrm{Xu} \mathrm{C}$, Wang $\mathrm{Y}$, Yang $\mathrm{H}$, et al. Association between cancer incidence and mortality in web-based data in China: Infodemiology study. $J$ Med Internet Res 2019;21:e10677.

32 Yang $\mathrm{H}$, Li S, Sun L, et al. Effects of the ambient fine particulate matter on public awareness of lung cancer risk in China: evidence from the Internet-based big data platform. JMIR Public Health Surveill 2017;3:e64.

33 China Internet Network Information Center. Chinese internet users search behavior study report. Beijing, China: CINNC, 2019.

34 Zhao C, Yang Y, Wu S, et al. Search trends and prediction of human brucellosis using Baidu index data from 2011 to 2018 in China. Sci Rep 2020;10:5896.

35 Havelka EM, Mallen CD, Shepherd TA. Using Google trends to assess the impact of global public health days on online health information seeking behaviour in central and South America. J Glob Health 2020;10:010403.

36 Savelkoel J, Claushuis TAM, van Engelen TSR, et al. Global impact of World sepsis day on digital awareness of sepsis: an evaluation using Google trends. Crit Care 2018;22:61.

37 Ajbar A, Shepherd TA, Robinson M, et al. Using Google trends to assess the impact of global public health days on online health information-seeking behaviour in Arabian Peninsula. J Egypt Public Health Assoc 2021;96:4.

38 Ling R, Lee J. Disease monitoring and health campaign evaluation using Google search activities for HIV and AIDS, stroke, colorectal cancer, and marijuana use in Canada: a retrospective observational study. JMIR Public Health Surveill 2016;2:e156.

39 Scheres LJJ, Lijfering WM, Middeldorp S, et al. Influence of World thrombosis day on digital information seeking on venous thrombosis: a Google trends study. J Thromb Haemost 2016;14:2325-8.

40 Lippi G, Mattiuzzi C, Cervellin G. Do "Disease Awareness Days" work? A 5-year investigation using google trends. J Epidemiol Glob Health 2020;10:245-6. 
41 Wang W, Jiang B, Sun $\mathrm{H}$, et al. Prevalence, incidence, and mortality of stroke in China: results from a nationwide population-based survey of 480687 adults. Circulation 2017;135:759-71.

42 Kranenburg FJ, Kreuger AL, Arbous MS, et al. The effect of World blood donor day on digital information seeking and donor recruitment. Transfusion 2017;57:2458-62.

43 Mahroum N, Adawi M, Sharif K, et al. Public reaction to Chikungunya outbreaks in Italy-Insights from an extensive novel data streamsbased structural equation modeling analysis. PLoS One 2018;13:e0197337.

44 Lecouturier J, Rodgers H, Murtagh MJ, et al. Systematic review of mass media interventions designed to improve public recognition of stroke symptoms, emergency response and early treatment. BMC Public Health 2010;10:784.

45 Zhao J, Li X, Liu X, et al. Changing the strategy and culture of stroke awareness education in China: implementing stroke 1-2-0. Stroke Vasc Neurol 2020;5:374-80.

46 Liu Y-B, Liu L, Li Y-F, et al. Relationship between health literacy, health-related behaviors and health status: a survey of elderly Chinese. Int J Environ Res Public Health 2015;12:9714-25.

47 Zhou $\mathrm{M}$, Wang $\mathrm{H}$, Zeng $\mathrm{X}$, et al. Mortality, morbidity, and risk factors in China and its provinces, 1990-2017: a systematic analysis for the global burden of disease study 2017. Lancet 2019;394:1145-58.

48 Wu S, Wu B, Liu M, et al. Stroke in China: advances and challenges in epidemiology, prevention, and management. Lancet Neurol 2019;18:394-405.

49 Games S. A college student was coma and admitted to Hospital, with a diagnosis of stroke, because of playing games for three days from day to night during the Mid-Autumn festival holiday, 2017. Available: $\mathrm{http} / / / g a m e s . s i n a . c o m . c n / g / f / 2017-10-08 /$ fymrqmq0900984.shtml [Accessed Oct 10 2020].

50 Phillips CA, Barz Leahy A, Li Y, et al. Relationship between statelevel google online search volume and cancer incidence in the United States: retrospective study. J Med Internet Res 2018;20:e6.

51 Noar SM, Ribisl KM, Althouse BM, et al. Using digital surveillance to examine the impact of public figure pancreatic cancer announcements on media and search query outcomes. J Nat/ Cancer Inst Monogr 2013;2013:188-94.

52 Abedi V, Mbaye M, Tsivgoulis G, et al. Internet-based informationseeking behavior for transient ischemic attack. Int J Stroke 2015;10:1212-6.

53 Cooper CP, Mallon KP, Leadbetter S, et al. Cancer internet search activity on a major search engine, United States 2001-2003. J Med Internet Res 2005;7:e36.

54 Chiu APY, Lin Q, He D. News trends and web search query of HIV/ AIDS in Hong Kong. PLoS One 2017;12:e0185004.

55 Mei X, Zhong Q, Chen G, et al. Exploring health literacy in Wuhan, China: a cross-sectional analysis. BMC Public Health 2020;20:1417.

56 Allem J-P, Leas EC, Caputi TL, et al. The charlie sheen effect on rapid in-home human immunodeficiency virus test sales. Prev Sci 2017; $18: 541-4$

57 Folyovich A, Biczó D, Béres-Molnár KA, et al. Assessment of the efficiency of stroke awareness campaigns in Hungary. J Stroke Cerebrovasc Dis 2018;27:1770-4. 